\title{
The Mechanical Properties of Oil Palm by Using Semi-Damp Dryer
}

\author{
Sakultala Wannapakhe ${ }^{1, *}$ and Khridsadakhon Booddachan ${ }^{1}$ \\ ${ }^{1}$ Department of Agricultural Engineering for Industry, Faculty of Industrial Technology and Management, \\ King Mongkut's University of Technology North Bangkok, 129 Moo 21, Tumbol Noen-Hom, \\ Amphur Muang, 25230, Prachinburi Province, Thailand
}

\begin{abstract}
Hot air drying of palm fruit is a simple method but results in low grade palm oil. The steaming of palm fruit results in high grade palm oil but it requires a wastewater treatment process. Both methods have both advantages and disadvantages, therefore if they were combined, it can result in the better grades of oil, which should be encouraged for farmers in Thailand to apply. This research aimed to determine mechanical characteristics of semi-damp dryer for oil palm. The results of a compression and relative humidity tests were used as the criteria for the tests. The oil palm semi-damp dryer was used in this research. The oil palm semi-damp dryer used the aerosolized technique with $100{ }^{\circ} \mathrm{C}$ hot water as a sprayer and a humidifier for the oil palm in the dryer. The purpose was to reduced palm fruit hardness. The study use tenera palm from Prachinburi province and neighborhood of Thailand. The drying time for testing was 1, 2, 3 and 4 hours. The temperature for testing was 70, 90 and more than $100^{\circ} \mathrm{C}$. The results of the compression force of oil palm by using a semi-damp dryer were lower than using a hot air drying. The compression was lower than using hot air drying. The best of mechanical characteristics palm was baking with semi-damp dry at $90{ }^{\circ} \mathrm{C}$ in 3 hours. Compression force was $0.675 \mathrm{kN}$ and relative humidity value was $57.18 \%$. The palm oil was tested for the \%FFA and DOBI and showed that the grade of palm oil by using semi-damp drying was fair but still edible grade.
\end{abstract}

Keyword. Oil palm drying, Semi-damp dryer, Oil palm semi-damp drying, Oil palm mechanical properties

\section{Introduction}

The main process in palm oil production is drying or steaming of palm bunches to inhibit the enzyme reaction that will generate free fatty acids (FFA) and also help the palm fruits to be easily removed from the bunch. The drying operations is primarily influenced by the different drying parameters. Cosme-De Vera et al., (2021) studied and compiled research on drying methods under different drying conditions [1]. Jitwiriya et al., (2020) studied about heat loss analysis of continuous drying oven with outside conveyor chain [2]. The mathematical model can be designed and analyzed for the drying oven before building the hot air oven. For farmers in Thailand, the baking process is an easy-to-use process. It does not require a system for management with the wastewater generated by the palm steaming process. Although oil palm drying has the advantages of being easy-to-use and does not require wastewater management, the dehydrated palm fruit has the disadvantage of being unable to separate palm meat and palm seeds kernels. As a result, the palm oil obtained from the extraction process is lower grade than the palm oil obtained from the palm meat alone. If farmers are able to separate palm meat and palm seeds to enter the oil extraction process, they will get quality oil from palm meat which can be sold at a better price. Kanchanaworavanich et al., [3], National Institute for Materials Science, 2005, analyzed the advantages and disadvantages of steamed and nonsteamed palm bunch drying. Ekarat Vaiyanitet et al., [4] developed the new system of palm bunch drying without using the steam. This helps removing the moisture from the palm, makes the palm off the shell more easily, and also inhibits the formation of free fatty acids. Therefore, the palm oil has good quality in A grade with low humidity and low fatty acids. In the last step, there is no need to chase away moisture from the oil again. It can save energy. And when not using water in the production process, it does not cause wastewater. Shehu et al., (2019) [5] studied in kinetics of thermal hydrolysis of crude palm oil with mass and heat transfer in a closed system. The deterioration of bleachability index (DOBI) and carotene content decreased by more than $90 \%$ and $95 \%$, respectively, after $90 \mathrm{~min}$ of heating at $473 \mathrm{~K}$, while at a temperature of $353 \mathrm{~K}$, the DOBI and carotene content decreased by less than $10 \%$ for all samples with different initial water content. The increase in temperature and water content resulted in an increase in $\%$ FFA accumulation. There are also other studies that studies on the implementation of the process, from oil to analyze and create [6-12]. 
From the study it was found that drying and steaming had different advantages and disadvantages. The advantages of each of these were designed to inhibit the enzyme reactions that will produce free fatty acids (FFA) and also help the palm fruits to be easily removed from the bunch and without the need for a wastewater treatment process. It was suitable for application to the farmers of Thailand. Therefore, to achieve a breakthrough in this regard, the researcher had an idea to learn about drying semi-damp palm oil for baking. The researchers had designed and built a semi-damp oil palm bunch dryer. After baking, the fruit is used to test the mechanical properties of palm oil after each drying temperature and humidity. Moreover, the semi-damp palm oil was studied for the basic properties of palm oil.

\section{Materials and methods}

\subsection{Experimental setup and procedure}

To test for mechanical properties of palm oil, the Wannapakhe et al., [13] researched on a hot air dryer with closed-loop oscillating heat pipe with check valves (CLOHP/CV) for reducing energy in drying as shown in Fig. 1. The heat generator was a $4,000 \mathrm{~W}$ heater. The hot air from the heater that had passed through the chamber before being released into the atmosphere was used as a source of heat to the CLOHP/CV. When the CLOHP/CV were heated, the heat was transferred to the air before it enters the heater, it was reducing the energy in the drying process. It was added to humidify the air in the hot air chamber. The size of the baking chamber can contain up to 10 kilograms of palm oil fruits, the maximum temperature was $120{ }^{\circ} \mathrm{C}$. The ware forming machine from nature pulp by Juntralux and Watanasriyakul [14] as shown in Fig. 2, it was applied in the press of oil palm fruit to produce palm oil. The machine had the section of a vacuum for sucking water out of the mold, the liquid palm oil was sucked and released through the liquid outlet.

\subsection{Operating conditions}

For testing, the drying time was 1, 2, 3, and 4 hours. The temperature for testing was 70,90 , and $110^{\circ} \mathrm{C}$. The hot air velocity was $0.5 \mathrm{~m} / \mathrm{s}$. The palm fruits (2 kilograms per testing) used for the test were Tenera varieties from the area of Kabin-Buri District, Prachinburi Province and neighborhood. In increasing the moisture, the boiling water can be increased at $99.7{ }^{\circ} \mathrm{C}$ and the water pressure up to 1.2 bars.

Then, the palm fruits after drying were tested for finding the compression force by using Universal Testing machine model NRI - TSS500 - 2S. The palm oil was tested for finding the FFA and DOBI value. The FFA and DOBI of palm oils were tested as follows [15]. Grade A crude palm oil (CPO) is controlled with a chemical value of FFA (Free Fatty Acid) not more than 5\% of the amount of CPO per unit and DOBI value not lower than 2.0. The appearance of the oil is yellow to red and thick and it is viscous. Grade B crude palm oil is controlled with a chemical value of FFA (Free Fatty Acid) at a level of not more than $8-10 \%$ of the amount of CPO per 1 unit. Its appearance is a color between yellow, red and dark brown. It depends on the production in the palm drying process of each producer that will affect the burnt palm fruit or the cleanliness of the palm fruit before the extraction process.

\subsubsection{Finding FFA}

Prepare Sodium Hydroxide $(\mathrm{NaOH})$ into the burette by weighing $0.4 \mathrm{~g}$ of Sodium Hydroxide into the $250 \mathrm{ml}$ shampoo bottle and pour $100 \mathrm{ml}$ of pure refining water into the $250 \mathrm{ml}$ shampoo bottle. Use the stirring rod to stir the solution to be mixed well. After that, pour it into the burette. Bring the obtained palm liquid into the titrate process for finding FFA by putting the crude palm oil into the oven and setting the temperature at $115{ }^{\circ} \mathrm{C}$ to dehydrate for 2 hours. Weigh $5 \mathrm{~g}$ of palm oil to put into the $250 \mathrm{ml}$ shampoo bottle. Pour $50 \mathrm{ml}$ of ethanol 95 $\% \mathrm{v} / \mathrm{v}$ into the shampoo bottle containing the palm oil. Drop 1-2 drops of phenolphthalein solution into the bottle and perform titrate process until the sample turns constant pink. The volume of $\mathrm{NaOH}$ solution (V) was recorded to calculate the FFA as equation 1.

$$
\text { FFA }(\text { wt. } \%)=\frac{V \times N \times 25.6}{M}
$$

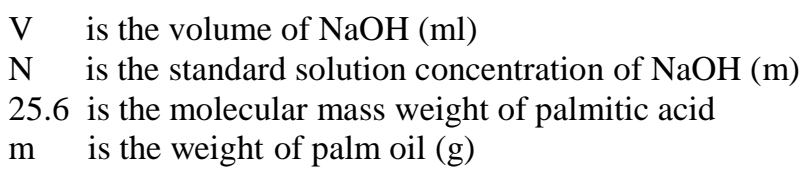

\subsubsection{Finding $D O B I$}

Put the obtained palm oil into Spectrophotometer to find DOBI by putting the crude palm oil into the oven and setting the temperature at $115{ }^{\circ} \mathrm{C}$ to dehydrate for 2 hours. Put the palm oil into the glass tube and measure the value by using Spectrophotometer. The wavelengths for the set absorbance test were 446 and $269 \mathrm{~nm}$. The absorbance was recorded to calculate the DOBI by using equation 2 .

$$
\mathrm{DOBI}=\mathrm{Abs}_{446} / \mathrm{Abs}_{269}
$$




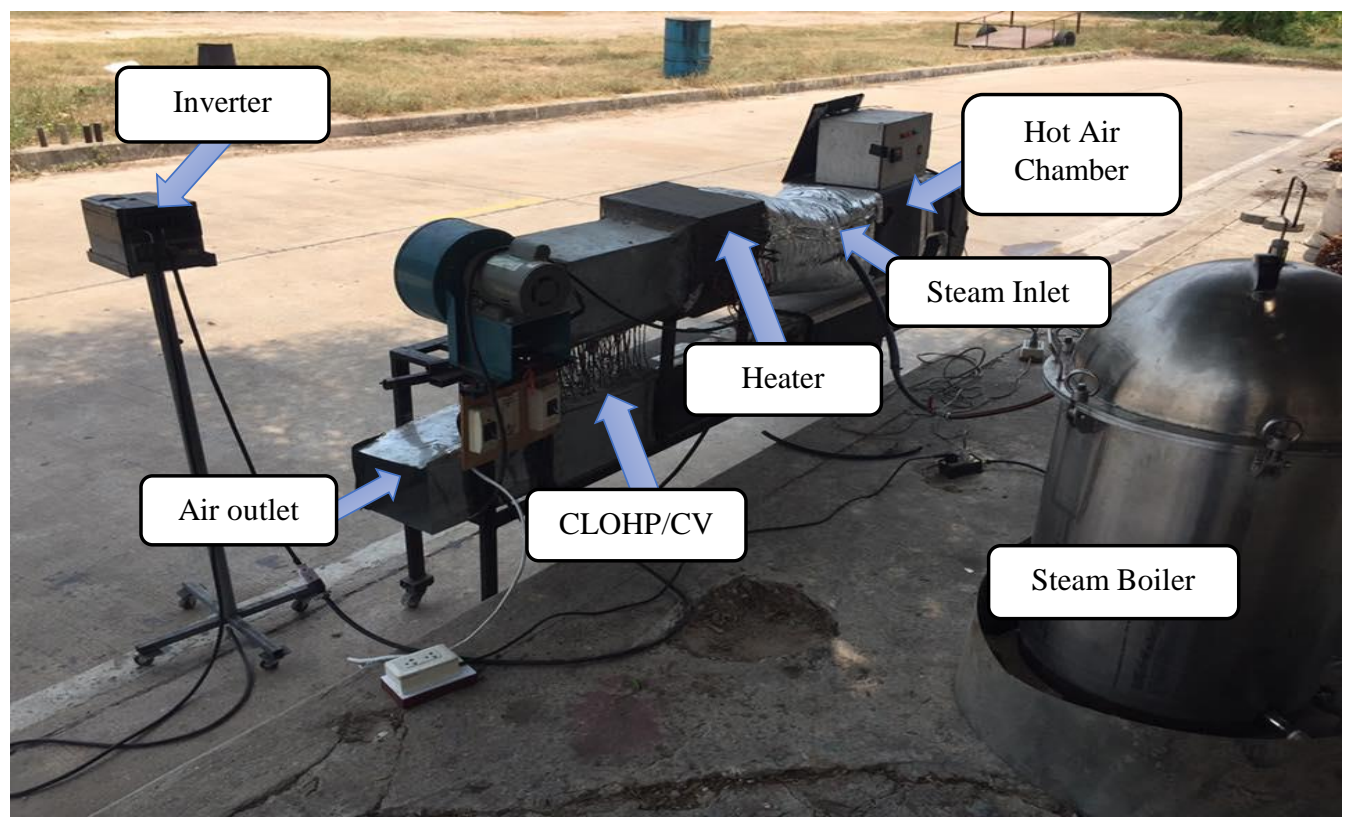

Fig. 1. The semi-damp dryer

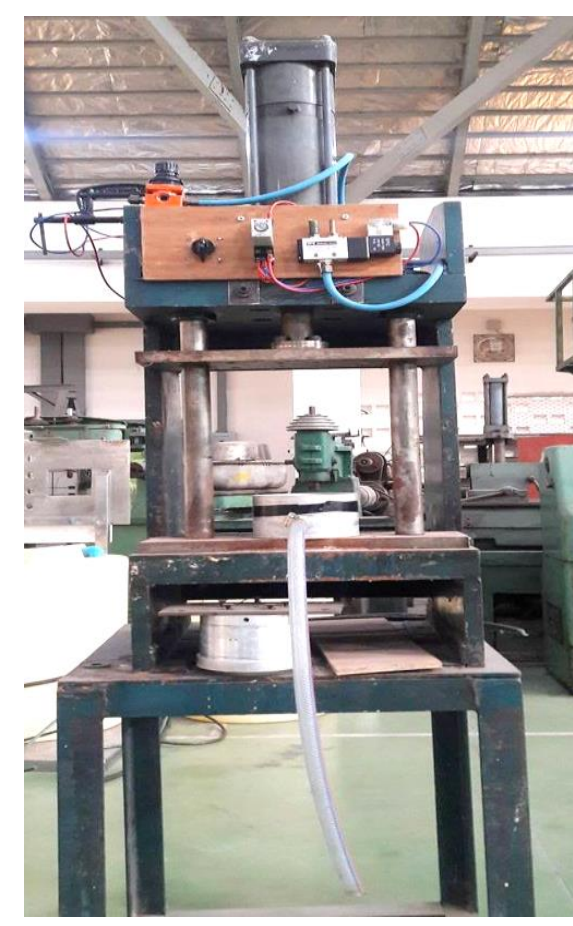

Fig. 2. The ware forming machine from nature pulp [14]

\section{Results and discussions}

\subsection{The results of the study on air conditions inside the drying chamber}

Data from a study that tested a palm hot air and semidry. The relative humidity of both baking treatments was measured as shown in figure $6-8$. If the air temperature was raised to more than $100{ }^{\circ} \mathrm{C}$, the air in the palm fruit drying chamber cannot be semi-humidified. For measurements in the air temperature range of 70 and 90 ${ }^{\circ} \mathrm{C}$, in the case of the hot air drying process, the hot air drying humidity was the percentage of about 5-20. In the case of the hot air semi-damp drying process, the hot air drying humidity was the percentage of about 37-60.

\subsection{The results of the study on mechanical properties of palm fruits after a drying process}

As shown in figure 3-4, the heat-treated palm fruit has a brown skin color and dry palm. The semi-dampened palm has a dark red skin color and the palm was moist enough with water. When the dried palm fruit was tested for mechanical properties by using the Universal Testing Machine model NRI - TSS500 - 2S as figure 5. The test results were shown in figure 9-12. As the baking temperature increases, the compression force required to press decreases. Due to the ripening of the palm fruit, it had an effect on the pulp of the palm fruit was soft. Compared with the drying process, it was found that the palm dried by using the hot air drying has a higher compression force value than the semi-dryer at all drying temperatures. in case of the drying temperature was more than $100{ }^{\circ} \mathrm{C}$, it was found that the compression force used was similar between hot air drying and semidamp drying. Because in the condition of drying at a temperature of more than $100{ }^{\circ} \mathrm{C}$, the humidity of the air inside the drying chamber was not much higher than that of the general hot air dryer. It resulted in a semi-dry drying at temperatures exceeding $100{ }^{\circ} \mathrm{C}$ no different from hot air drying. 


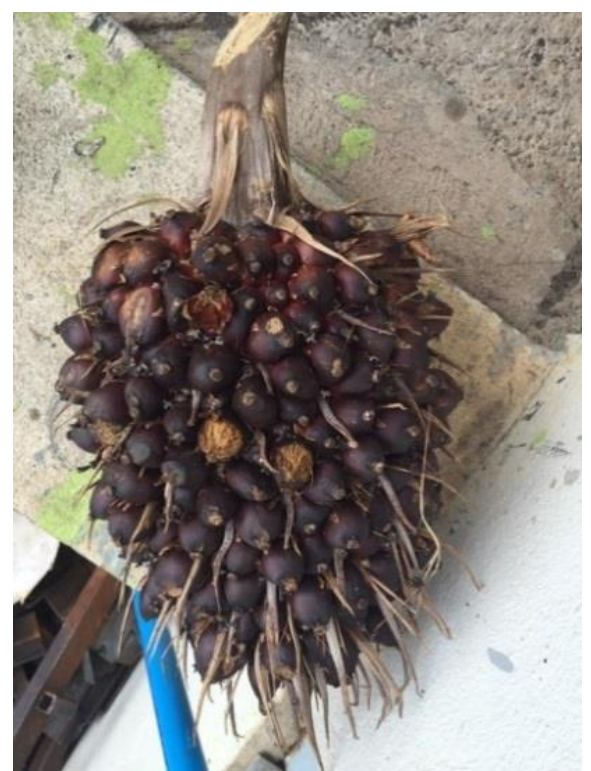

Fig. 3. The heat treated palms

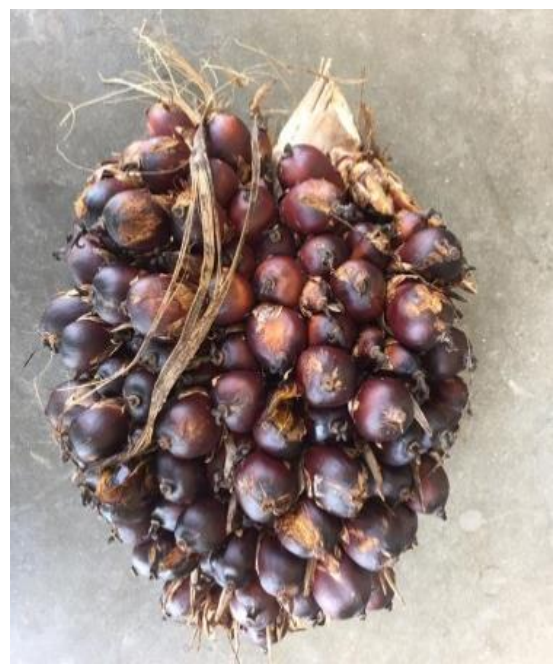

Fig. 4. The semi-damp dried palms

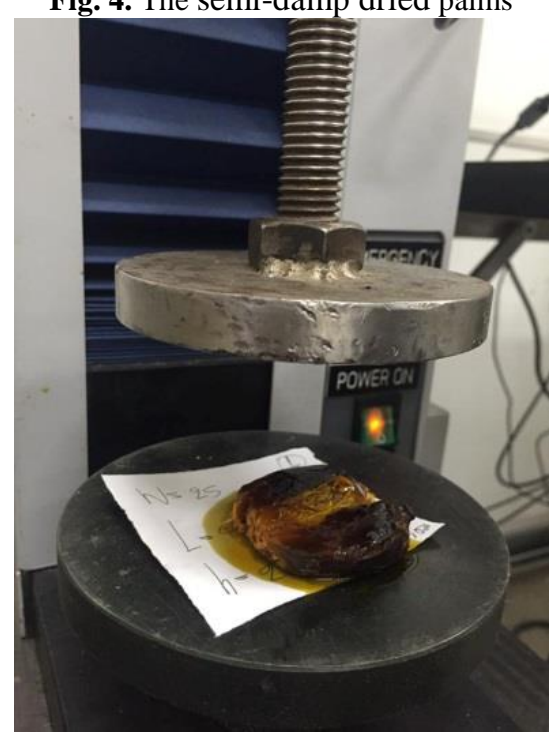

Fig. 5. The compression force testing by Universal Testing Machine model NRI - TSS500 - 2S

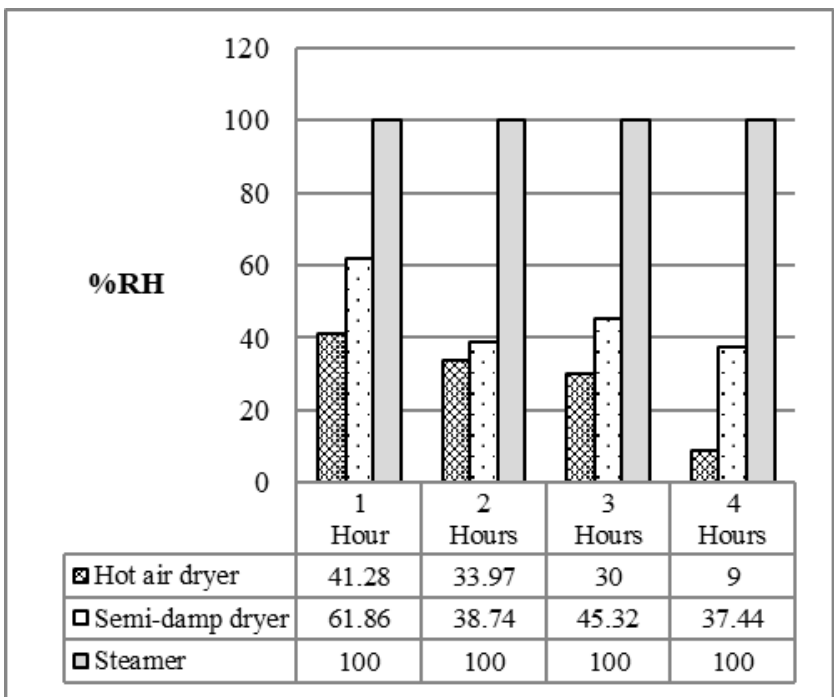

Fig. 6. Relative humidity in case of drying at $70{ }^{\circ} \mathrm{C}$

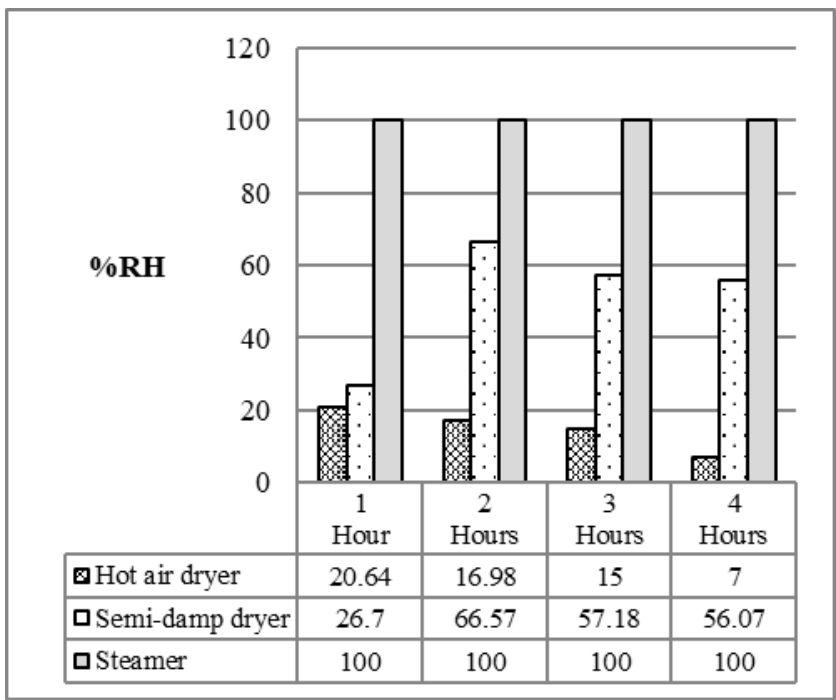

Fig. 7. Relative humidity in case of drying at $90{ }^{\circ} \mathrm{C}$

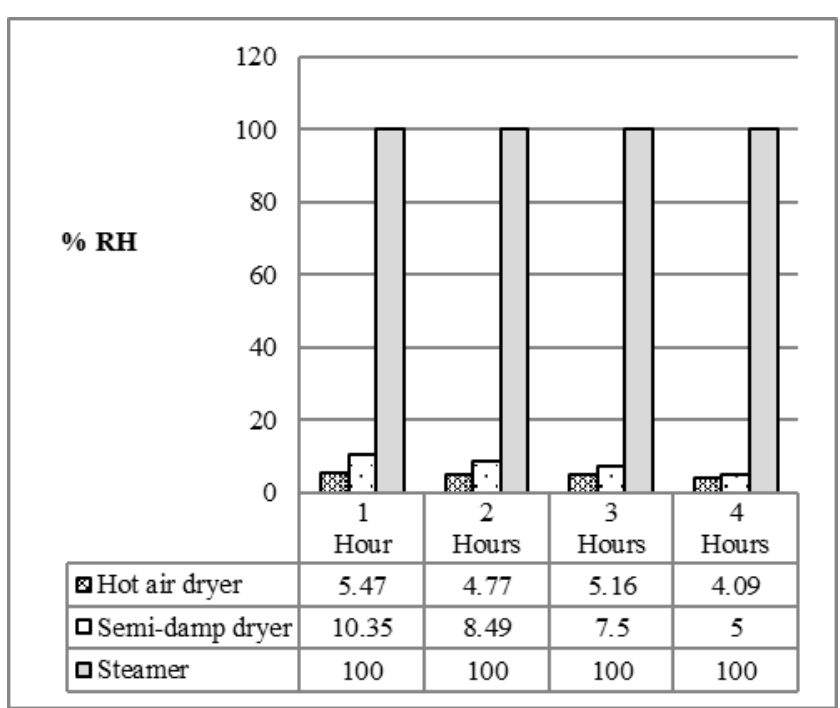

Fig. 8. Relative humidity in case of drying at $110^{\circ} \mathrm{C}$ 


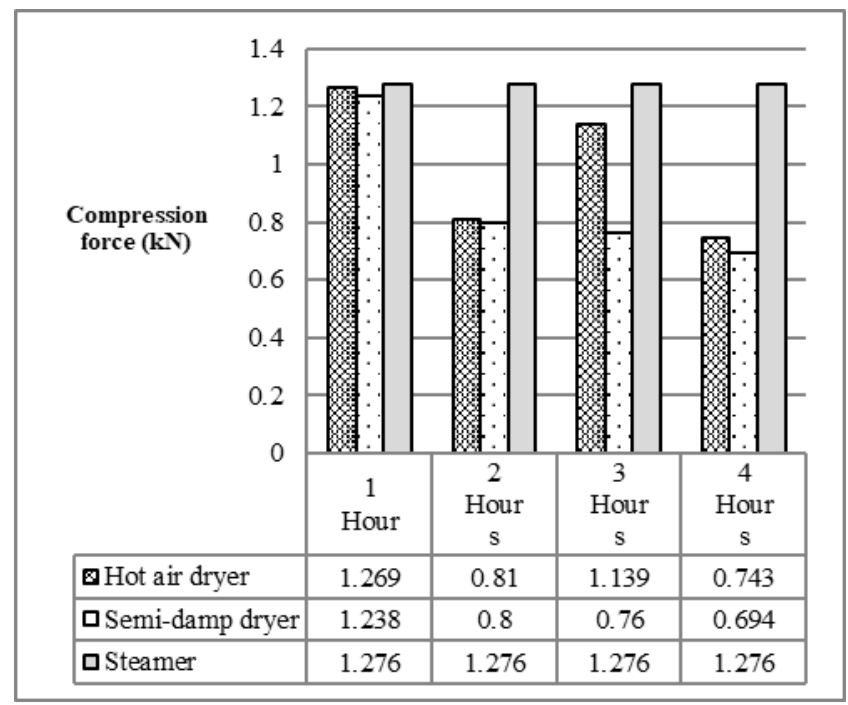

Fig. 9. Compression force in case of drying at $70^{\circ} \mathrm{C}$

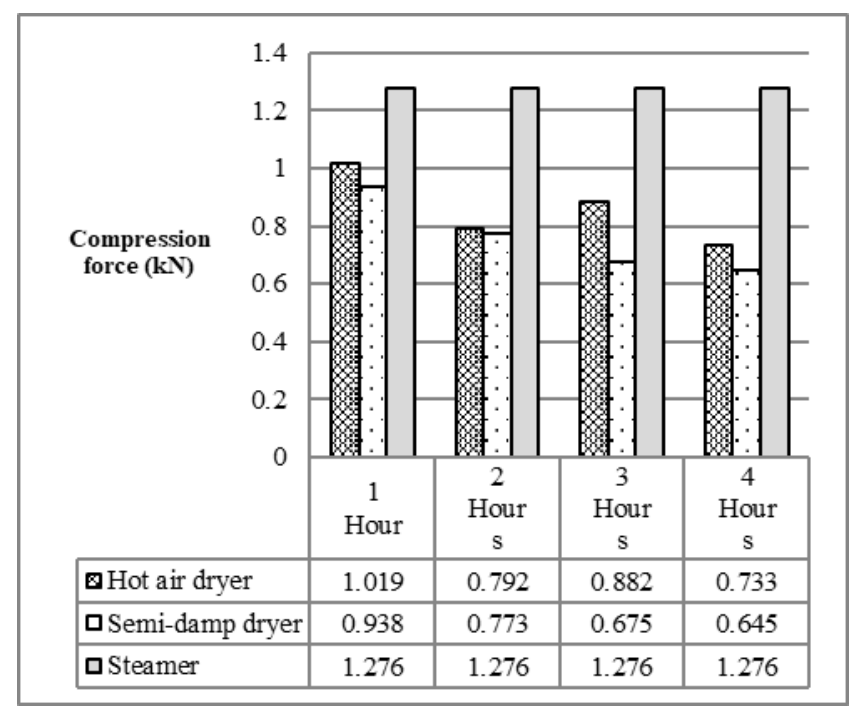

Fig. 10. Compression force in case of drying at $90{ }^{\circ} \mathrm{C}$

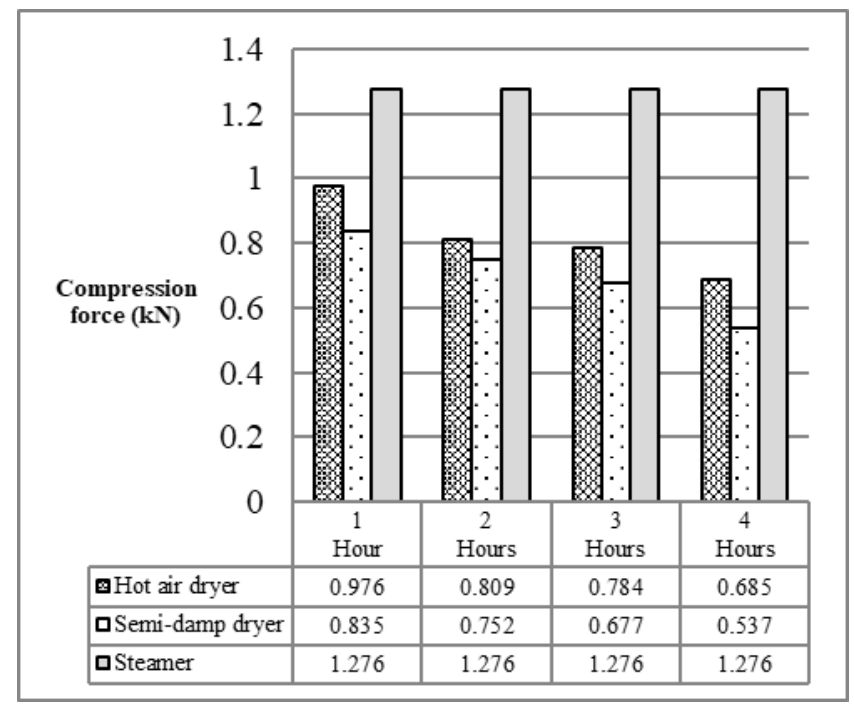

Fig. 11. Compression force in case of drying at $110^{\circ} \mathrm{C}$

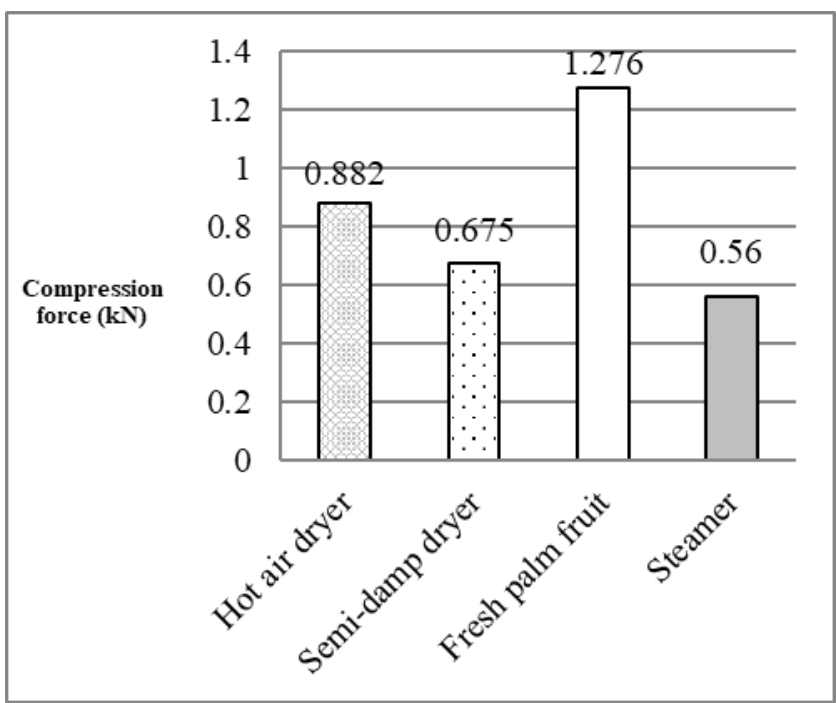

Fig. 12. Comparison of the compression force of $90{ }^{\circ} \mathrm{C}$ at drying time 3 hours

\subsection{The results of testing properties of palm oil}

From the test to study the condition of semi-damp drying, it was found that if the drying air temperature was increased more than $100{ }^{\circ} \mathrm{C}$, semi-damp drying could not occur. The properties of palm oil were tested at temperatures of 70 and $90^{\circ} \mathrm{C}$ only, and the drying time was 3 hours. From the test results as shown in figure 13, the results of the experiment showed that drying at $90^{\circ} \mathrm{C}$ for 3 hours, stored for 1 day in semi-damp drying, and was the best at \% FFA. Because the semi-damp was helped to stop lipolysis better than hot air drying. The semi-damp drying, hot steam can penetrate into the palm fruit. As a result, the palm pulp obtained from the semidamp drying process was better than the conventional hot air drying process which produced free fatty acids in the palm fruit. The free fatty acid content in oil is an indicator of the quality of the oil that will be used for biodiesel production or consumption. If the \%FFA is high, it will easily oxidize in nature, causing a rancid smell. When the palm oil was analyzed for DOBI in palm oil by center of excellence-oil palm Kasetsart university, Thailand, it was found that the CPO from hot air drying at $90{ }^{\circ} \mathrm{C}$, drying time was 3 hours, DOBI value was 0.63 . The oil grade was based on the DOBI value of the freshness of crude palm oil. If the value is lower than 2.2, it means that the CPO was not fresh. The oil was not suitable for consumption. The CPO from semi-damp drying at $90{ }^{\circ} \mathrm{C}$, drying time 3 hours, DOBI value was 2.35 , CPO was in grade $2.31-2.92$, which was usable quality. The oil was suitable for consumption. The results are similar to the research of Pootao and Kanjanapongkul [15]. Increasing voltage, temperature and time resulted in higher yield and lower FFA while quality of extracted palm oil still met the standard. 


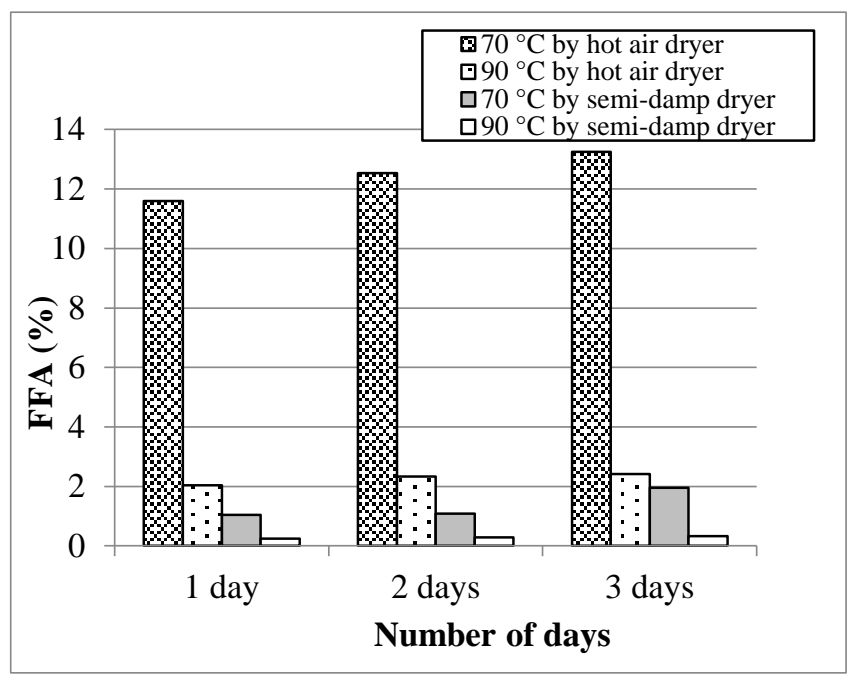

Fig. 13. The free fatty acid content (FFA) of hot air drying and semi-damp drying

\section{Conclusion}

Semi-dryer, if the air temperature was more than $100{ }^{\circ} \mathrm{C}$, it was not possible to make the air in the semi-moisture drying chamber. The mechanical properties test by using Universal Testing Machine, it was found that when the drying temperature increased, the compression force used to press decreased. The palm drying using hot air dryer has higher compression force values than semidamp dryer at all test temperatures. Except for the semidamp dryer at the drying temperature of more than 100 ${ }^{\circ} \mathrm{C}$, it was found that the compression force was similar between hot air drying and semi-damp drying. Therefore, it can be concluded that if semi-damp drying should be in the range of $70-90{ }^{\circ} \mathrm{C}$. The properties of palm oil from the study data were conducted at $70^{\circ} \mathrm{C}$ and $90^{\circ} \mathrm{C}$, both hot air and semi-damp drying for 3 hours, with the oil being stored for 1 day, 2 days and 3 days. It was found that the best value of CPO was semi-damp drying at $90{ }^{\circ} \mathrm{C}$ for 3 hours of drying time with 1 day of CPO left, \%FFA was $0.25 \%$. The best DOBI test was at Semi-damp drying at $90^{\circ} \mathrm{C}$, drying time 3 hours, with DOBI value of 2.35. From the test results, it can be concluded that semi-damp drying should be done. Because the properties of CPO were a higher grade than $\mathrm{CPO}$ obtained from hot air drying.

\section{Acknowledgements}

The author would like to express their appreciation to King Mongkut's University of Technology North Bangkok for providing financial support for this study.

\section{References}

1. F.H. Cosme-De Vera, A.N. Soriano, N.P. Dugos, R.V.C. Rubi, A comprehensive review on the drying kinetics of common tubers, Applied Science and Engineering Progress, 14, 2 (2021): 146-155
2. J. Weerayut, C. Tonkid, N. Udomkiat, Y. Pisit, Heat Loss Analysis of Continuous Drying Oven with Outside Conveyor Chain, Applied Science and Engineering Progress, (2020)

3. K. Boonyarak, Study and analyze the advantages and the disadvantages of non-steam and steam-based palm oil extraction systems. National Institute for Materials Science, (2015)

4. V. Ekarat, Non-steam palm oil extraction system. National Institute for Materials Science, (2015)

5. Shehu, E. Umar, Kinetics of thermal hydrolysis of crude palm oil with mass and heat transfer in a closed system, Food and Bioproducts Processing, 118 (2019): 187-197

6. S. Yusoff, Renewable energy from palm oilinnovation on effective utilization of waste, Journal of cleaner production, 14, 1 (2006): 87-93

7. Y. Basiron, Palm oil production through sustainable plantations, European Journal of Lipid Science and Technology, 109, 4 (2007): 289-295

8. P. Somporn, Gheewala, H. Shabbir, Full chain energy analysis of biodiesel production from palm oil in Thailand, Applied energy, 86 (2009): 209-214

9. M.J. Junaidah, A.R. Norizzah, O. Zaliha, Effect of sterilization process on deterioration of bleach ability Index (DOBI) of crude palm oil (CPO) extracted from different degree of oil palm ripens, $\mathbf{3}$, 4 (2013): 322-327

10. B.A. Orhevba, O. Chukwu, V. Oguagwu, Z.D. Osunde, Effect of moisture content on some quality parameters of mechanically expressed neem seed kernel oil. The International Journal of Engineering and Science, 2, 8 (2013): 01-07

11. I.M. Ogan, D. Marie-Josée, N. Michael, Palm oil: Processing, characterization and utilization in the food industry-A review, Food bioscience, 10 (2015): 26-41

12. B. Murad, S. Nadia, S. Jumat, D-Optimal Design Optimization for the Separation of Oleic Acid from Malaysian High Free Fatty Acid Crude Palm Oil Fatty Acids Mixture Using Urea Complex Fractionation, Applied Science and Engineering Progress, 14, 2 (2021): 175-186

13. S. Wanapakhe, T. Chaiwong, M. Dandee, S. Prompakdee, Hot air dryer with closed-loop oscillating heat pipe with check valves for reducing energy in drying process, Procedia Engineering, 32 (2012): 77-82

14. J. Noppadol, W. Somnuk, Design and construction of ware forming machine from nature pulp, IE Network Conference, Phetchaburi, Thailand, (2012): 1770-1775

15. P. Sunisa, K. Kobsak, Pretreatment of oil palm fruit using ohmic heating, The 16th TSAE National Conference and the 8th TSAE International Conference, Bangkok, Thailand, (2015) 